on dementia and learning disabilities. The project was supported by Burdett Nursing Trust and local commissioners who wanted to see improved standards of EOL care.

The Six Steps + programme has been running for the last 12 months and currently has 66 organisations and 131 individuals registered. The programme has been very successful and has delivered real service improvements eg the last post death audit (412 deaths), demonstrated that $42 \%$ of individuals who died had an Advance Care Plan in place and the number of inappropriate hospitals admissions fell from $40 \%$ to $23 \%$.

The project truly promotes integrated working. The hospice equality mark is now published in the local authority's online public directory. Organisations stated they wanted to have a local quality mark linked to the local hospice which families recognise. The EOL Link Forum is pivotal to service integration as well as being a vehicle for ongoing audit and monitoring end of life outcomes.

The programme does not provide any educational credit therefore Skills for Care was approached to accredit the programme. This resulted in a national mapping tool being created to map the Six Steps to the new Quality Credit Framework EOL qualifications.

The next step for the project is to create a train the trainer programme to help others implement Six Steps + in their area. Hospices cannot provide all EOL care and they have an important role in enabling providers in their communities to deliver good quality equitable EOL care for all.

\section{P52 QUALITY END OF LIFE CARE FOR ALL (QELCA ${ }^{\odot}$ )}

Liz Bryan', Marie Cooper', Anita Hayes'; 'St Christopher's Hospice, Sydenham, United Kingdom, ${ }^{2}$ Help the Hospices, ${ }^{3}$ NHS Improving Quality (formally National End of Life Care Programme (NEOLCP))

\subsection{6/bmjspcare-2013-000591.74}

The Department of Health has concluded that the non-specialist workforce needs to develop the necessary attitudes and skills in order to deliver consistently high quality care for people approaching the end of life and is looking for beacons of best practice in relation to practice development initiatives $(\mathrm{DoH}$, 2008).

St Christopher's Hospice has designed a training programme which not only role-models end of life care to the participants but equips and empowers them to deliver better care to patients on their return to practice. QELCA $\odot$ was designed to be delivered by hospice nurses to nurses working in hospitals. Teams of acute nurse clinical managers from the same department spend 5 days based at the hospice in small groups of three or four. Using the hospice setting as a learning resource, nurses are offered a first-hand experience of observing and being alongside specialist nurses as they care for patients at the end of life. In addition to this practice experience the 5-day programme combines classroom discussion and reflection facilitated by experienced specialist palliative care nurses. The programme then continues with six months facilitated Action Learning Sets (ALS) so that action plans for self, team and organisation, formulated by the participants on the final day of their hospice experience, can be supported in practice and learning from the programme consolidated.

In partnership with St Christopher's and Help the Hospices, the National End of Life Care Programme (NEoLCP), through the Transform Programme (NEoLCP, 2013), piloted QELCA ${ }^{\odot}$ across 17 sites. 21 hospices were involved and a total of 137 acute nurses attended the QELCA $^{\odot}$ programme. Evaluation data were collected at four stages across the pilot timeline using mixed methods comprising, survey questionnaires, semi-structured questionnaires and focus groups. A report outlined the findings and made recommendations for the further development of the programme.

\section{P53 QUALITY END OF LIFE CARE FOR ALL [QELCA] LEEDS}

Laura Speight, Steve Lawman; St Gemma's Hospice, Leeds, England

\subsection{6/bmjspcare-2013-000591.75}

Introduction St Gemma's Hospice and Leeds teaching hospitals trust are involved in a national end of life care programme's pilot. This is an education initiative called 'Quality End of Life Care for All’ [QELCA] developed by St Christopher's hospice. Aims

- Share expertise of Hospice care with nurses working in a variety of settings where End Of Life Care [EOLC] was being provided.

- Empowerment of generalist nurses to make a difference in practice, providing EOLC.

- Address with nurses issues of anxiety, fear, and lack of insight/self-awareness when providing EOLC.

- Equip nurses to remain in meaningful emotional contact with patients/relatives whilst preserving professional integrity.

- Prevention of emotional exhaustion and risk of 'burn out'.

\section{Methods}

- 5 days placement at St Gemma's Hospice.

- Combination of facilitated classroom learning and practical experience. [IPU, Community, Day services.]

- Reflect on learning and formulate action plan for priorities for change.

- Action plan is supported by facilitated action learning [AL] over six sessions.

Results

- Positive relationships/ networks between acute and hospice staff.

- Constructive comments made regarding EOLC provision in different clinical areas.

- Each QELCA candidate focusses on something to change/ implement within clinical practice based on Hospice experience.

- During AL sessions, progress discussed/ action plans made. Changes occurred, with management support.

Discussion Attendance and feedback from the course is so far very positive, candidates enjoyed being in the different environment. AL sets not well attended therefore criteria could be changed for future courses. Results from AL are positive showing that changes had been implemented and worked in practice.

Conclusion/ Future recommendations Since the introduction of the DoH's End of life care strategy 2008, there has been a focus on patients' wishes at end of life especially on Preferred Place of Care, [PPC]. Courses such as QELCA, enable healthcare professionals to expand their knowledge in such a specialist area and provide such care through a process of innovation and change. 